\title{
Cliticization and Old Chinese Word Order
}

Edith Aldridge, University of Washington

Whether Old Chinese was an OV or VO language remains a highly controversial question in Chinese linguistics. Xu (2006) proposes that basic word order in this language was mixed between VO and OV. This claim is based primarily on the fact that pronominal objects preceded the verb in certain contexts. One such context is when negation appears higher in the clause. (1a) shows VO order in the absence of negation. (1b) shows a pronominal object appearing before the verb and following the negator.

$\begin{array}{llll}\text { (1) a. 胡 為 而 食 我? } & \text { (Lü Shi Chunqiu 12.3) } \\ \text { Hu wei er si wo? } & \\ \text { what for Conj feed } 1 & \\ \text { 'Why are you feeding me?' } & \\ \text { b. 我 饑 而 不 我 食。 } & \\ \text { Wo ji er bu wo si. } & \\ 1 \text { starve Conj not } 1 \text { feed } & \end{array}$

The purpose of this paper is to argue against using pronoun fronting under negation as evidence for underlying OV order in Old Chinese. I propose instead that underlying order was VO, while OV order in negated clauses was derived. As principle evidence, I show that OV order was not free or arbitrary but was subject to structural constraints. In late Archaic Chinese of the $4^{\text {th }}$ and $3^{\text {rd }}$ centuries BCE, when the negator was $b u$ 'not', there were a number of structural contexts in which pronoun fronting did not occur. (2a) shows that a pronoun did not cross a clause boundary. (2b) shows that objects of prepositions were likewise unable to front. In (2c), a pronoun base generated in the specifier of VP did not move.

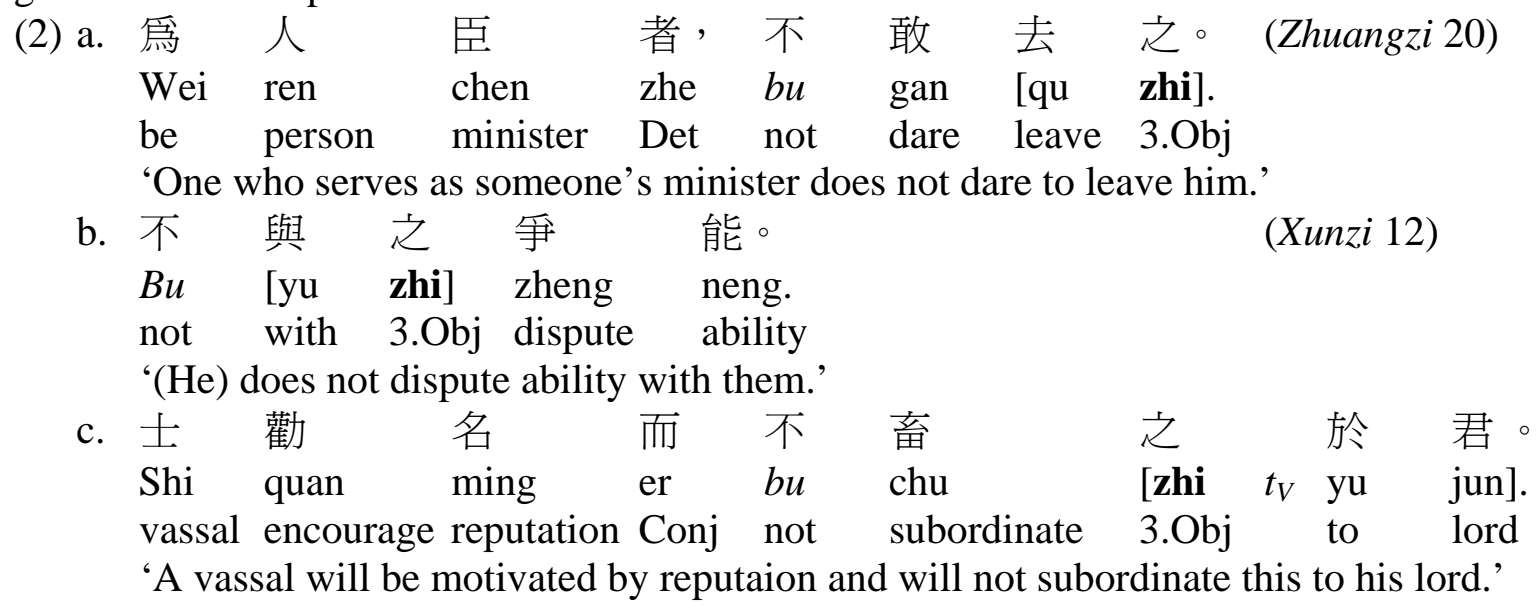

(Hanfeizi 32)

Clearly, it is not the case that a pronominal object could arbitrarily appear before the verb in the context of negation. On the other hand, a movement analysis does account for the pattern in (1) and (2). The descriptive generalization is that pronoun fronting was possible only when this pronoun was base-generated as the complement of the verb in the clause containing the negator. One straightforward way to account for the positioning would be to say that prosodically weak 
VP-internal pronouns in this period underwent a very local type of cliticization, specifically head-movement and left-adjunction to the verb.

(3)

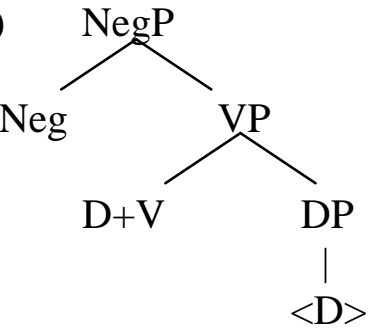

In the Morphological Component, a pronoun was linearized in this position if negation appeared immediately to its left. Otherwise, the pronoun and verb underwent Local Dislocation (Embick \& Noyer 2001) to return it to post-verbal position.

The head-movement analysis accounts for the locality constraints seen in (2). Adjunction to the embedded verb in (2a) does not serve to place the pronoun in a position adjacent to negation, so it is reordered post-syntactically to follow the verb. As sister to a preposition in (2b), headmovement will not take place, since incorporation only takes place between a verb and a pronominal complement. (2c) is also accounted for, since incorporation from the VP specifier position would violate the Head Movement Constraint.

Note that the claim that archaic Chinese pronouns which front under negation are prosodically weak elements is not controversial (Feng 1996). This status is also suggested by the fact that heavier pronouns like yan '3.Dat' did not undergo this fronting.

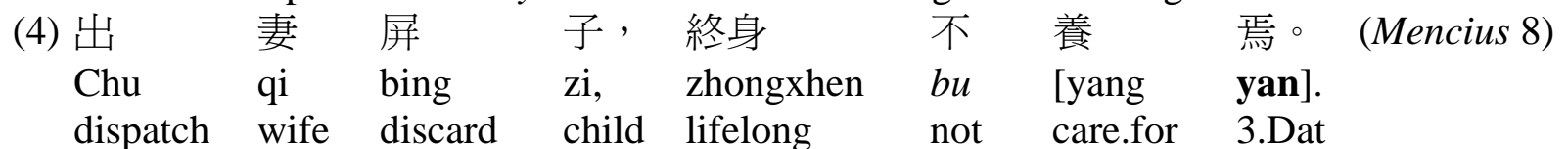

'(He) sent his wife away and abandoned his children and did not care for them for the rest of his life.’

However, the facts are actually more complicated than a simple head-movement approach would allow. As (5) shows, other negators such as mo 'none' were not subject to the constraints on $b u$ 'not' shown in (2). A pronoun has raised across an embedded clause boundary to adjoin to mo 'none' in (5). This suggests that head-movement could not have taken place in the syntax, since this would incorporate the pronoun to the verb, preventing it from moving further, e.g. into the matrix clause.

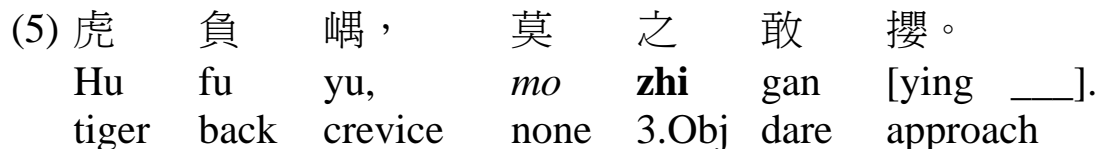

(Mencius 14)

'The tiger backed into a crevice and no one dared to approach it.'

Furthermore, fronting to bu 'not' was also less constrained in earlier Archaic Chinese. The examples in (2) are taken from texts dating from the 3rd-4th centuries BCE. Prior to the 4th century BCE, however, bu 'not' could trigger raising across a clause boundary or from a specifier position. 
(6) a. 余不 女 忍 殺。

$\mathrm{Yu} \quad b u$ ru ren [sha

I BU you endure kill

'I cannot bear to kill you.'

b. 無 適 小 國

$\mathrm{Wu}$ shi xiao gou,

not go small country

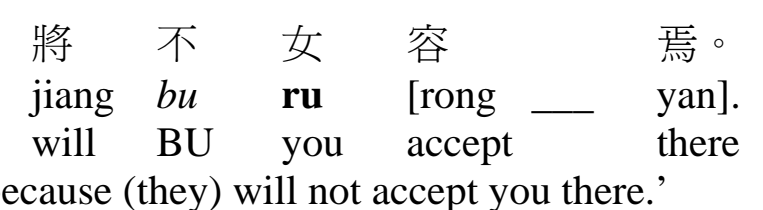

'Do not go to a small country, because (they) will not accept you there.'

(Zuozhuan, Zhao 1)

(Zuozhuan, Xi 7)

I propose an analysis of pronoun fronting prior to the 4th century BCE along the general lines of Halpern's (1995) analysis second position clitics, in which pronouns undergo movement in the syntax the edge of some specific domain, in this case the maximal projection hosting the attracting negator. The pronoun is then realigned postsyntactically. Specifically, I propose that the pronoun undergoes Local Dislocation (Embick and Noyer 2001) with its host negator in the morphological component.

(7)

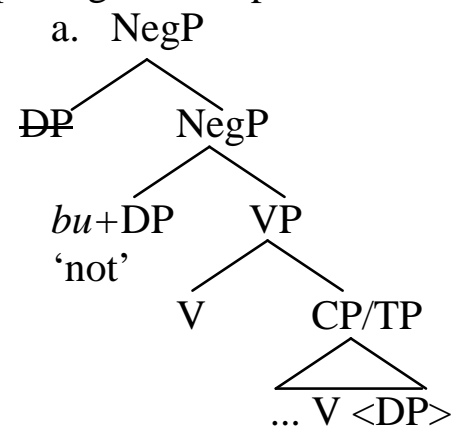

b.

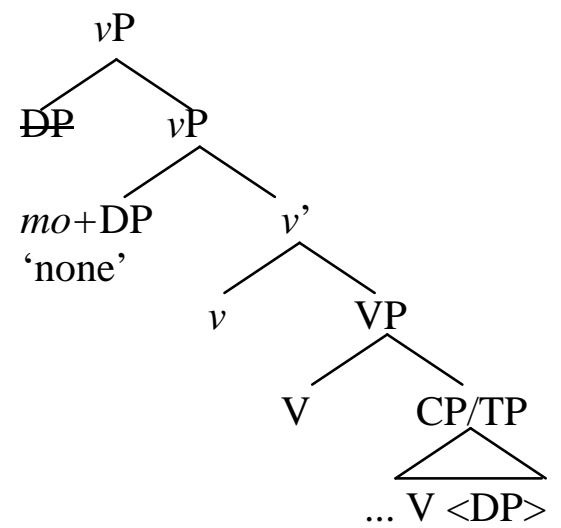

After the 4th century BCE bu 'not' lost the ability to trigger pronoun movement in the syntax. The effects of cliticization were preserved on a limited basis, however, by lowering in the morphological component. In the following structural configuration, in a VP which is in a local configuration with a negator, i.e. residing in the same phase, the verb could lower to a pronominal sister. This creates Neg-pro-V order post-syntactically. Lowering maintains the empirical coverage of the paradigm in (2), since lowering moves a head downward to the head of its sister. We therefore expect to see effects of the Head Movement Constraint, albeit in reverse.

(8)

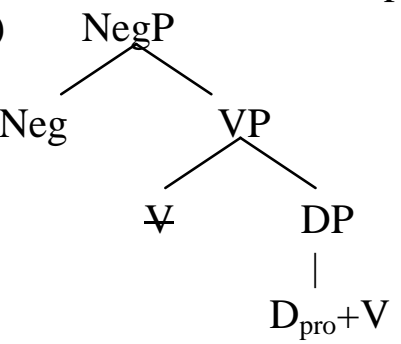

Additional support for the diachronic scenario in which long clitic climbing was replaced with post-syntactic lowering comes from a third negator, the aspectual negator wei 'not.yet'. Before the 4th century BCE, wei also triggered long distance raising, like mo 'none' and bu 'not'. 


$$
\begin{aligned}
& \text { 楚君之惠, 未敢忘。(Zuozhuan Xi 28) } \\
& \text { Chu jun zhi hui, wei zhi gan [wang _ ] } \\
& \text { Chu lord Gen generosity not.yet 3.Obj dare forget }
\end{aligned}
$$

From the $4^{\text {th }}$ century BCE, however, long distance raising with wei 'not.yet' became optional. (10a) shows raising across a modal verb, while (10b) shows the pronoun in situ, embedded under a modal verb.
a. 日 夜 思之, 猶未文能得。
Ri ye si zhi, you wei zhi neng [de__].
day night think 3.Obj still not.yet 3.Obj can obtain
'(They) think about this day and night and still are not able to obtain it.'

$\begin{array}{cllll}\text { b. 不 仁 } & \text { 而 } & \text { 取 } & \text { 名 } & \text { 者, } \\ \text { Bu ren } & \text { er } & \text { qu } & \text { ming } & \text { zhe, } \\ \text { BU benevolent } & \text { Conj } & \text { get } & \text { name } & \text { Det } \\ \text { 嬰 未 } & \text { 得 } & \text { 聞 } & \text { 之 } & \text { 也。 } \\ \text { Ying wei } & \text { de } & \text { [wen } & \text { zhi ] } & \text { ye. } \\ \text { Ying not.yet } & \text { can hear } & \text { 3.Obj } & \text { Decl }\end{array}$

(Lüshi Chunqiu 12.3)

'I, Ying, have not yet heard of someone who is not benevolent but has a good reputation.’

Furthermore, there are examples in which the verb appears to have lowered to its complement, so long as the negator still resides in the same phase as the VP.

$\begin{array}{lllllll}\text { 自 古 } & \text { 及今, 未 } & \text { 嘗 } & \text { 之 } & \text { 有 也。 } \\ \text { zi } & \text { gu } & \text { ji jin, } & \text { wei chang [vp you } & \text { [DP zhi } & \text { you] } & \text { ye. } \\ \text { from antiquity } & \text { to now not.yet previously } & 3 . \text { Obj have } & \text { Decl }\end{array}$

'From antiquity to the present day, there has never before been an instance of this.'

(Guanzi 12)

The coexistence of clitic climbing with the lowering option strongly suggests a change in progress between the types of cliticization illustrated in (7) and (8). More importantly, the structural constraints on pronoun positioning, coupled with the diachronic facts that more long distance fronting was later replaced with extremely local head movement, argues fervently against the base generation approach of Xu (2006) and allows historical Chinese syntax to be understood from a universal linguistic perspective.

\section{References}

Xu, Dan. 2006. Typological Change in Chinese Syntax. Oxford University Press. Embick, David and Rolf Noyer. 2001. Movement Operations after Syntax. Linguistic Inquiry 32:4:555-595.

Feng, Shengli. 1996. Prosodically constrained syntactic changes in early archaic Chinese. Journal of East Asian Linguistics 5.323-371.

Halpern, Aaron. 1995. On the Placement and Morphology of Clitics. Stanford, CA: CSLI. 